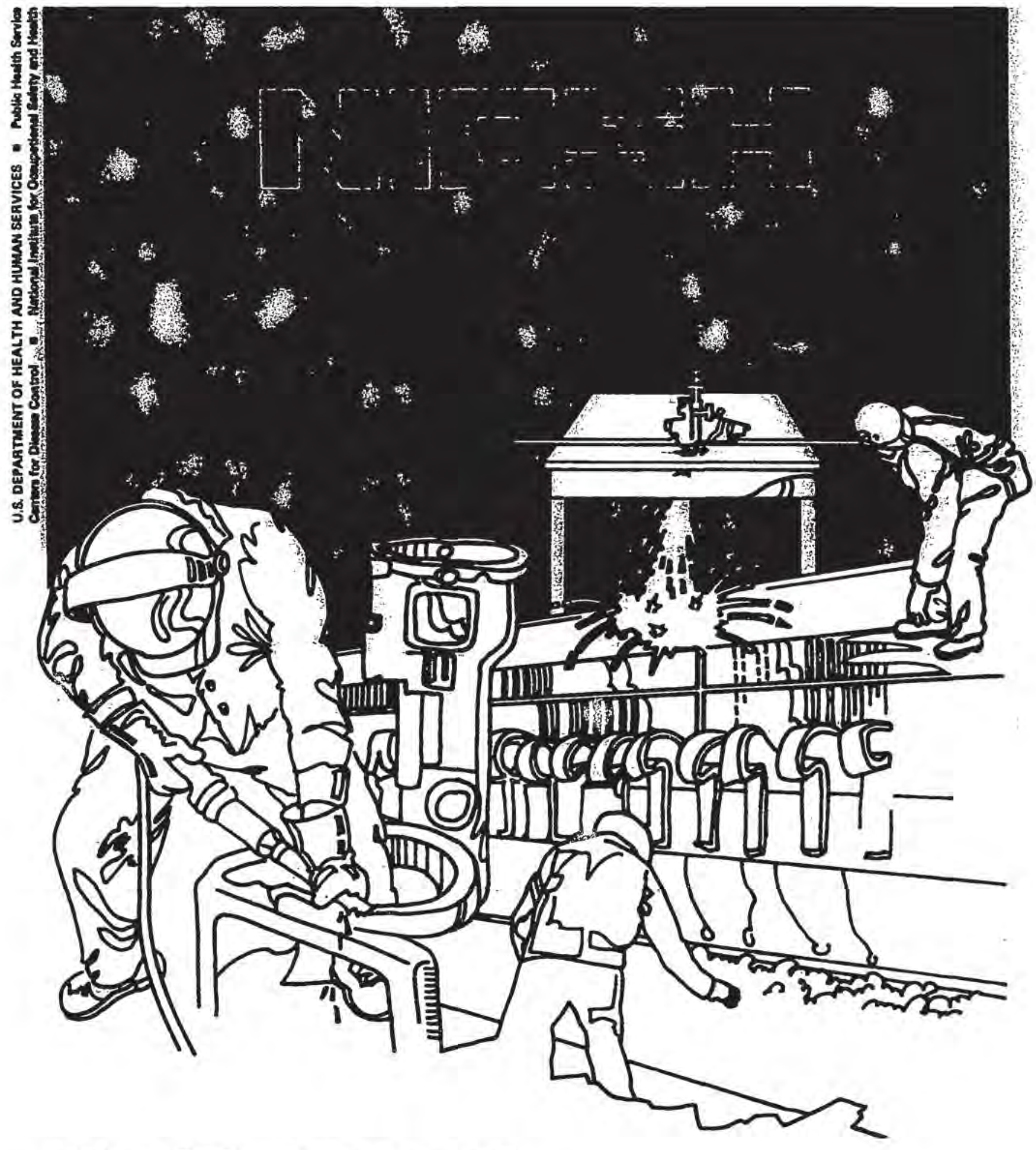

Health Hazard

Evaluation

Report

HETA 82-272-1276

BOEING VERTOL COMPANY

PHILADELPHIA, PENNSYLVANIA 


\section{PREFACE}

The Hazard Evaluations and Technical Assistance Branch of NIOSH conducts field investigations of possible health hazards in the workplace. These investigations are conducted under the authority of Section $20(a)(6)$ of the Occupational Safety and Health Act of 1970, 29 U.S.C. 669(a)(6) which authorizes the Secretary of Health and Human Services, following a written request from any employer or authorized representative of employees, to determine whether any substance normally found in the place of employment has potentially toxic effects in such concentrations as used or found.

The Hazard Evaluations and Technical Assistance Branch also provides, upon request, medical, nursing, and industrial nygiene technical and consultative assistance (TA) to Federal, state, and local agencies; labor; industry and other groups or individuals to control occupational health hazards and to prevent related trauma and disease.

Mention of company names or products does not constitute endorsement by the National Institute for Occupational Safety and Health. 
HETA $82-272-1276$

MARCH 1983

BOEING VERTOL COMPANY

PHILADELPHIA, PENYSYLVANIA
NIOSH INVESTIGATORS:

Walter Chrostek, IH

Gary M. Liss, M.D.

Gene Moss, HP

\section{SUMMARY}

On April 15, 1982, the National Institute for Occupational Safety and Heal th (NIOSH) received a request from the Boeing Vertol Company to evaluate reported employee health complaints in the Purchased Parts Stores (PPS) and Packaging areas of Building 3-25, including anxiety, nausea, eye strain and headache. These were thought possibly to be related to working under high pressure sodium vador (HPSV) lamps and working with storage boxes dioped in sulfur.

NIOSH investigators conducted an initial medical and environmental survey in Mav 1982 and a follow-up survey in July 1982. Air samples were collected for evaluation of exposures to sulfates, sulfites and sulfur dioxide. A calibrated photometer was used to measure the workplace fllumination in units of 1ux. Self-administered questionnaires were completed by 37 employees in the Packaging Area who worked under HPSV lamps; by 26 employees in PPS who worked under HPSV lamps and with sulfur boxes; and by 19 employees in the Pattern Shoo, who worked in a different building which did not have either HPSV lamps or sulfur boxes. To further assess possible color distortion, NIOSH investigators administered the Farnsworth-Munsell 100-Hue Test to 15 employees in Building 3-25.

Environmental sampling demonstrated non-detectable levels of sulfite; sulfate levels ranged from 9-14 ug/ $\mathrm{M}^{3}$ and sulfur dioxide levels ranged from 7-10 $u g / \mathrm{M}^{3}$ - NIOSH recommended standard $1300 \mathrm{ug} / \mathrm{M}^{3}$; OSHA standard 13,000

$\left.u g / M^{3}\right)$. The illumination levels in some parts of the buflding were far less than obtimal. There was much concern over glare, particularly in relation to the video display terminals.

The prevalence of reported symotoms of eye fatigue ( $52 \%$ vs $30 \%)$ and loss of smell (30\% vs $0 \%$ ) was significantly greater in DPS (where sulfur boxes and lower illumination were present) than in packaging (where boxes were absent and higher illumination levels existed). The prevalence of reoorted blurred vision (59\% vs $30 \%$ ) and of eye irritation ( $43 \%$ vs $0 \%$ ) was significantly qreater in packaging (HPSV lamps present) than in pattern-makers (HPSV lamps absent). Results of the 100 Hue Test were consistent with a slight impairment, under HPSV lamps, of discrimination of certain colors.

Although no serious adverse health effects were noted, symptoms related to the eyes and minor abnormalities of color discrimination, possibly related to HPSV lamps and exposure to sulfur containers were detected. Recommendations to improve the lighting situation are presented in Section VIII.

KEYWORDS: SIC, 3721 ( Aircraft), High Pressure Sodium Vapor Lamps. 
Page 2 - Boeing Vertol, HETA 82-272

INTRODUCTION

On Apri1 15, 1982, the National Institute for Occupational Safety and Heal th (NIOSH) received a request from the Boeing Vertol Company to evaluate reported employee health complaints in the Purchase Parts Stores (PPS) and Packaging Areas of Building 3-25. The request identified a number of employee symptoms: depression, anxiety and crying episodes in PPS, apparently attributed to storage boxes dipped in sulfur for fire retardation and stiffening; and nausea, eye strain and headache in both PPS and Packaging, attributed to working under high presure sodium vapor (HPSV) lamps.

NIOSH conducted an initial medical and environmental survey in Tate May 1982 and a follow-up survey in July 1982.

\section{BACKGROUND}

Boeing Vertol Company is engaged in the design and manufacture of helicopters. It employs approximately 4500 people. In December 1981, a new building, 3-25, was opened by the company. It houses a number of storage areas including PPS and packaging departments (Figure 1), which had been previously scattered in various other buildings. The distribution of lighting fixtures in these areas is shown in Figure 2. High pressure General Electric 400-watt sodium vapor lamps ("Lucalox") are the major sources of illumination; there are also a few fluorescent lamp fixtures and two sunlight portals. All HPSV lamps were mounted in standard reflectors having some degree of diffusing capability (i.e. lamps did not present themselves as point sources). The spectral emission of these lamps, according to the manufacturer's specification, is shown in Figure 3. The spectrum contains wavelengths throughout the visible radiation region with peak emissions occuring in the wavelength region from 575 to 610 nanometers $(\mathrm{nm})$. A negligible amount of $u 1$ traviolet radiation is produced by these lamps.

At about the same time that building 3-25 opened, the company introduced new storage boxes (Convoy, Incorporated, Canton, Ohio) for use in PPS. These consisted of corrugated cardboard that had been immersed by the manufacturer in $99.9 \%$ pure molten sulfur for fire retardation and stiffening. According to the box manufacturer, in the absence of combustion, it was believed that only sulfur dust would come off the boxes. 
Page 3 - Boeing Verto1, HETA 82-272

IV. MATERIALS AND METHODS

A. Environmental: Industrial hygiene

Four employee exposures and two general air samples in Building 3-25, Purchased Parts Storage, were evaluated for sulfates, sulfites and sulfur dioxide on June 3,1982 . The air samples were collected on cellulose filters impregnated with potassium hydroxide using sampling pumps operating at approximately 1.5 liters per minute. These samples were subsequently analyzed by NIOSH Method P\&CAM No. 268.21

B. Environmental: Optical Radiation

Since the spectral content of HPSV lamps is well known, it was necessary only to perform illumination measurements for this study. A calibrated Photo-Research System 500 Photometer was used to measure the workplace illuminance in units of lux. The photometer was held about 5.2 meters below the light fixtures which is approximately the position where workers would locate. The survey was performed in Building 3-25 during the afternoon of July 1, 1982 in those locations where workers reported symptoms. At least two measurements were made at each location, and the highest result was recorded.

C. Medical/epidemiology

On the initial survey, the NIUSH investigators gave self-administered questionnaires to all available day shift employees in PPS and packaging. The questionnaire addressed a number of eye/visual symptoms as well as taste, sme11, mood and other bodily functions. The four eye-related questions asked are displayed in Appendix I. As a comparison group (i.e. not working under HPSV 1amps), all employees in the Pattern Shop (Building 3-56) who were concurrently being assessed as part of HETA $82-146$, which did not involve eye symptoms or neurotoxins, completed the same questionnaire. The questionnaire addressed two time periods: "right now or in the past 30 minutes" and "in the past week but not counting today". The responses for the latter period were not properly completed for all respondents. It was possible that the instructions were not completely understood by all those filling out the questionnaire. Thus, only responses for the immediate time frame were analyzed.

To further assess the problem, and because of reports of color distortion observed in the few previous investigations of indoor use of HPS lamps, the Farnsworth-Munsel1 100-Hue Test22 was

administered on the return visit to 15 individuals. This test offers a simple method for testing color discrimination; the object is to arrange a series of colored caps in order according to color. With the assistance of a consultant psychologist specializing in visual 
Page 4 - Boeing Verto1, HETA 82-272

physiology, the test was administered to 15 employees and was scored by computer at the Wills Eye Hospital, Philadelphia, Pennsylvania. Changes in color perception produced by HPS light were sought by repeating the 100-Hue procedure once with a standard light source and again at the work area under HPS light. To control for any learning effect, NIOSH investigators alternated the light source under which the subjects performed the test initially.

V. EVALUATION CRITERIA

1. Sulfur dust/ sulfur dioxide

Sulfur dust is irritating to the mucous membranes, particularly the eyes $1-2$, and can be associated with lacrimation (excessive tear production), photophobia (discomfort caused by ordinary light levels), conjunctivitis (inflammation of the surface of the eye) and blepharoconjunctivitis (conjunctivitis with involvement of the eyelids). In fact, eye irritation in humans associated with a concentration of 8 parts per million (ppm) of sulfur has been reported. 3 Associated with airborne sulfur dust is the danger of release of $\mathrm{SO}_{2}$ leading to the inhalation of irritant vapors.1

Sulfur dioxide is an irritant to the mucous membranes of the eye and respiratory tract. It has a pungent smell detectable at 3 $\mathrm{ppm}$. In low concentrations it can al so cause lacrimation, sneezing and coughing. 4 The irritant effects of $\mathrm{SO}_{2}$ are caused by formation of sulfurous acid (sulfites) on contact with moist membranes. 5,6 With continuous exposure, upper respiratory disease, partial loss of taste and partial loss of smell can occur. 7,8 Sulfuric acid appears, on a chronic basis, to be a more potent irritant than sulfur dioxide. 4 However the sulfate ion per se is not irritant, and the sulfates vary widely in irritant potency depending on the cation found with the sulfate radical (anion). 4

There are no specific standards for sulfites or sulfates, except for sulfuric acid $\left(1 \mathrm{mg} / \mathrm{M}^{3}\right.$ or $1000 \mathrm{ug} / \mathrm{M}^{3}$ as a time-weighted average). The OSHA standard for sulfur dioxide is $13,000 \mathrm{ug} / \mathrm{M}^{3}$ ( 5 parts per million) as an 8-hour time-weighted average, while the NIOSH recommended standard is $1,300 \mathrm{ug} / \mathrm{M}^{3}(0.5 \mathrm{ppm}) .5,20$ 
Page 5 - Boeing Vertol, HETA 82-272

2. Health effects of sodium vapor lighting

There are a few documented reports of complaints, generally involving color changes and visual task distortions, associated with working under HPSV lights. Reports from schools 9 and industries10-11 emphasize eye strain, eye pain, headaches, glare, and color changes. It has been noted that in industrial situations where HPSV lamps are used for general illumination purposes, workers who are protanopes (redblind) may be severely handicapped due to the lack of color perception. A recent study reported a slight increase in body and adrenal gland weight in Sprague-Dawley female rats exposed to HPSV lamps.12,13,14 The study was reconfirmed recently at the National Institute of Environmental Health Sciences (NIEHS) 15 using the same protocol. The NIEHS study showed that rats born and reared under HPSV lamps have increased adrenal gland weight when compared to rats reared under daylight-simulating fluorescent lights. The authors concluded that the differences in adrenal weights were statistically significant and might be due to the spectral difference between the two sources. They were not able to show statistically significant differences between groups on stress or behavioral tests. A recent NIOSH report evaluating HPSV lamps at a large industrial plant concluded that no health effects could be directly attributed to the lamps.11 However, it was pointed out that the guideline values for optical radiation have been based on skin and ocular effects and not behavioral effects.

Few studies have been performed to assess the acceptability of HPS illumination. One study compared the acceptability of high intensity discharge sources for offices. 17 Fluorescent, metal halide, high-pressure sodium and metal halide high-pressure sodium sources were compared. No significant differences were found among the four lighting sources, by analysis of variance for time and for omission errors during a visual acuity task. For the color discrimination task, again no significant differences were observed. An Italian study 16 reported that under illumination produced by a high-pressure sodium lamp as compared to that under CW (cool white) light, color discrimination was found to be impaired, as assessed with the 100-Hue Test. A more recent study 18 found that mean performance of a simulated clerical task (multiple refocus task) in an office environment was significantly poorer under HPS light than under CW fluorescent light. This finding was independent of age and refractive state. It was felt that HPS light reduced many subjects' abilities to perform the task and that it does affect visual performance. 
Page 6 - Boeing Vertol, HETA 82-272

VI. RESULTS

A. Environmental: Industrial Hygiene

The environmental results are sumarized in Table I. Sulfate exposures ranged from 10 to 14 micrograms per cubic meter of air. All sulfite air samples collected were below the limit of detection, which was 4 micrograms per sample. Air levels of sulfur dioxide ranged from 7 to $10 \mathrm{ug} / \mathrm{M}^{3}$. This is well below both the OSHA standard and the NIOSH recommended standard.

B. Environmental: Physical Agents

As can be seen in Table II, the illumination in the Packaging Area is consistently higher than in the Purchased Parts Storage area. Since the fixtures are mounted at the same height in both areas, the illumination difference is accounted for by a greater density of lamps in the Packaging Area. The nature of the work in the Packaging Area demands a higher visual requirement and consequently the illumination is more critical. Table II also shows that certain places within the PPS area do not have sufficient illumination for satisfactory working conditions. This is most notable within the storage work zone. Finally, it is interesting to note from Table II that the illumination in the two areas with fluorescent lamps is much higher than that in areas with only HPSV .lamps. In the portion of the Packaging Area that used video display terminals (VDT) and microfilm readers, the glare reflected by the VOT screen face was very annoying to workers.

C. Medical/Epidemiology

1. Demographic data

Demographic data for the non-supervisory employees in the three departments from which subjects were seen (Purchase Parts Stores, Packaging and Pattern Shop) are shown in Table III. The ages were comparable; the packaging employees had a much greater proportion of females.

2. Sulfur-coated boxes/I11umination levels

NIOSH investigators noticed a sulfur-like odor when close to the boxes. The prevalence of positive responses was compared between storekeepers in PPS (sulfur boxes in work area) and packagers (no sulfur boxes in work area) (Table IV). Both groups worked under HPS lamps. The prevalence of reported 


\begin{abstract}
"hot, tired, aching eyes", by $16(62 \%)$; eye fatigue by $16(62 \%)$; and loss of smell by $7(30 \%)$ of 26 employees was significantly greater in PPS than in the Packaging Area [11(30\%), $11(30 \%)$ and $0(0 \%)$ of 37 , respectively]. The prevalence of reported "eye irritation" and loss of taste was also greater, but this difference was of borderline statistical significance. These symptoms are compatible with exposure to sulfur and sulfur dioxide as well as being associated with the low illumination levels noted above.
\end{abstract}

\title{
3. High-pressure sodium lamps
}

Because the employees in PPS had the possible confounding exposure to sulfur boxes, differences in symptoms attributable to HPSV lighting were sought between packers (who worked under HPSV lights but not with sulfur boxes) and pattern-makers in Building 3-56 who had neither exposure. Table $V$ shows these comparisons. The prevalence of symptoms of blurred vision [11(30\%) of 37$]$ and of eye irritation [16(43\%)] was significantly greater in the packers, who worked under HPSV lamps than in the pattern-makers, who did not [1(5\%), and $0(0 \%)$ of 19 , respectively]. There was a highly significant difference in the frequency of reporting of two or more of the four eye symptoms (Appendix A) between the packers (14 of 37) and pattern-makers (none of 19), as shown in Table VI.

The test results of the Farnsworth-Munsell 100-Hue Test were reported as a numerical error score, shown in Table VII. The square root-transformed scores distribute normally (19); differences were analyzed for those individuals with no evidence of defective color vision. Overall, color discrimination was significantly impaired $(p<0.05)$ under HPSV light in comparison with a standard light source. When examining subgroups by light source used for initial test, a significant difference was noted only for those performing the test under HPSV light first.

\section{DISCUSSION ANU CONCLUSIONS}

The higher prevalence of reported symptonis related to eyes, loss of taste and loss of smell in PPS, the detectable sulfur dioxide on environmental sampling and the odor noted in PPS are all compatible with exposure to sulfur dust and sulfur dioxide. The eye symptoms are also compatible with the lower illumination in PPS.

Comparing the packers and pattern-makers, the prevalence of reported symptoms of eye blurring and of eye irritation was significantly greater in the former group, who worked under HPSV lamps. These results may have been biased somewhat toward finding no difference because individuals in the (control) pattern-maker group were themselves exposed to potentially irritating substances, including epoxy resins. These complaints from workers in the packaging area 
Page 8 - Boeing Vertol, HETA 82-272

were very similar to studies concerning HPSV lamps reported in the literature. This is not surprising due to the high visual demand of workers in this area and the newness of the installation of these lamps (i.e. less than 6 months). Many of the workers had attempted to reduce the glare and overall scene brightness by the use of sunglasses.

Color distortion, which has also previously been noted in the literature, was reported in this study more frequently, but not significantly so. These symptoms were examined further in this survey with the administration of the 100-Hue Test. This testing revealed results that were consistent with a slight impairment, under HPSV light, of discrimination of certain colors. This is consistent with findings in the literature, but it is unclear whether this is related to the other symptoms reported by packaging workers.

VIII. RECOMNENDATIONS

1. The amount of sulfur dust generated by the boxes is likely to decrease with time. However, this type of box should be avoided in the future.

2. In the packaging area, attention should be given to rearranging tables to positions closer to fluorescent lamps, using indirect ceiling lighting, installing greater diffusion capability on lamp fixtures, reducing lamp wattage, removing or not using some HPSV lamps, increasing use of sunlight portals, and mixing different lamp types. Incorporation of some or all of these suggestions would help to effect a more pleasing visual working condition.

3. The VDT and readers could be re-arranged so that glare on to the screen is minimized. Anti-glare screens or screen shields could be installed.

4. Additional lamp fixtures should be installed in those parts of the storage area where illumination is excessively below any recommended standard (i.e. 0-10 1ux).

While these recommendations are made to improve lighting factors, it must be realized that workers may not like, or may not be accustomed to the type of light produced by HPSV lamps. Although the color produced by the HPSV 1amp may be annoying, there is no evidence that this light type is hazardous to one's health. 
Page 9 - Boeing Vertol, HETA 82-272

\section{REFERENCES}

1. Encyclopedia of Occupational Health and Safety. International Labour Office. Volume II. Geneva: McGraw-Hi11, 1972. D.1368.

2. Gosselin RE, Hodge et al. Clinical Toxicology of Commercial Products. 4th Edition. Baltimore: The Williams \& Wilkins Company, 1975.

3. National Institute for Occupational Safety and Heaith. Registry of toxic effects of chemical substances. 1980 Edition. Volume Two. p.668.

4. Casarett and Doull's Toxicology. The Basic Science of Poisons. Doull J, Klassen CD, Amdur MO (eds). Second Edition. New York: Macmillan Publishing Co, Inc, 1980. p.612-616.

5. National Institute for Occupational Safety and Health. Criteria for a recommended standard--occupational exposure to sulfur dioxide. Cincinnati, Ohio: National Institute for Occupational Safety and Health, 1974. (DHEW publication no. (NIOSH) 74-111).

6. Proctor NH, Hughes JP. Chemical hazards of the workdlace. Philadelphia: J.B. Lippencott Company, 1978.

7. Waldron HA. Lecture notes on occupational medicine. Londion: Blackwell Scientific Publications, 1976. pp.105-106.

8. National Institute for Occupational Safety and Health. Occupational diseases: a guide to their recognition. Revised ed. Cincinnati, Ohio: National Institute for Occupational Safety and Health, 1977. (DHEW (NIOSH) publication no. 77-181).

9. Mills LF, Anderson, FA. Report on classroom use of sodium vador 1amps. DHHS Publication (FDA) 82-8183. HHS Publication (FDA)

10. Lakowski $R, 01$ iver $K$. Modern industrial lighting and the protanope. Mod Probl Ophthal 1978; 19:105-108.

11. NIOSH Health Hazard Evaluation Report, May 1982. HETA 80-119-1103.

12. Dzaki $Y$, Wurtman R. Soectral Dower distribution of light sources effects growth and development of rats. Photochemistry and Photobiology 1979; 29:339-341.

13. Corth R. Comment on the Daper: Spectral power distribution of light sources effects growth and development of rats. 
Page 10 - Boeing Vertol, HETA 82-272

14. Ozaki Y, Wurtman R. Author's reply. Photochemistry and Photobiology 1979; 30:350-531.

15. Chignell CG, and Sik, RH. The effect of high pressure sodium vapor lamps on the rat. Submitted to Photochemistry and Photobiology (in press).

16. Serra A, Mascia C, Dessy C. Color discrimination under $C$ and High-Pressure $\mathrm{Na}$ illumination in normals and patients affected by various diseases. Mod. Prob1. Ophthal. 1978; 19:281-283.

17. Yuan SM, Bennett CA. The acceptability of HID task-ambient lighting for offices. Lighting Design \& Application 1980; $10: 51-56$.

18. Piper HA. The effect of HPS light on performance of a multiple refocus task. Lighting Design \& Application 1981; 11:51-56.

19. Kinnear PR. Proposals for scoring and assessing the 100-Hue Test. Vision Research 1970; 10:423-433.

20. Occupational Safety and Health Administration. OSHA Safety and Heal th Standards. 29 CFR 1910.1000 . Occupational Safety and Heal th Administration, revised 1980.

21. National Institute for Occupational Safety and Health, NIOSH National manual of analytical methods. Vol 5, 2nd ed. Cincinnati, OH: National Institute for Occupational Safety and Health, 1979. (DHEW (NIOSH) publication no. 79-141).

22. The Farnsworth-Munsel1 100-Hue Test for the examination of Color Discrimination. Manual by Dean Farnsworth. Revised 1957. Munse11 Color Company.

$X$. AUTHORSHIP AND ACKNOWLEDGEMENTS Report Prepared by:

Walter Chrostek, I.H. Regional Industrial Hygienist Region III 
Page 11 - Boeing Vertol, HETA 82-272

Field Assistance:

Gary M. Liss, M.D., M.S. Medical Officer Medical Section HETAB

C. Eugene Moss, M.S., M.P.H. Health Physicist Division of Biomedical and Behavioral Science

Michael E. Breton, Ph.D. Visual Physiology Wills Eye Hospital

Originating office:

Philadelphia, Pennsylvania

Hazard Evaluations and Technical Assistance Branch

Division of Surveillance, Hazard Evaluations, and Field'Studies

XI. DISTRIBUTION

1. Boeing Vertol Company, Philadelphia, Pennsylvania

2. Local 1069, UAW

3. OSHA, Region III

4. NIOSH, Region III 
Page 12 - Boeing Vertol, HETA 82-272

TABLE I

Boeing-Vertol Company

Philadelphia, Pennsylvania

HETA $82-272$

October 1982

Building 3-25 (Purchased Parts Storage)

Results of Sampling for Sulfate, Sulfite, Sulfur Dioxide (TWA)*

\begin{tabular}{|c|c|c|c|c|c|c|}
\hline Location & Sample \# & Time & Sulfite & Sulfate & $\begin{array}{l}\text { Sulfur } \\
\text { Dioxide }\end{array}$ & Remarks \\
\hline $\begin{array}{l}\text { Row 7-8 } \\
\text { Foreman's }\end{array}$ & 1 & $7: 45-15: 15$ & $4^{\star \star \star}$ & 14 & 10 & General Air \\
\hline $\begin{array}{l}\quad \text { desk } \\
\text { Employee } \\
\text { Employee } \\
\text { Employee } \\
\text { Employee } \\
\text { Row } 3-4\end{array}$ & $\begin{array}{l}2 \\
3 \\
4 \\
5 \\
6 \\
7\end{array}$ & $\begin{array}{l}7: 40-15: 15 \\
7: 30-14: 51 \\
7: 48-15: 16 \\
7: 26-15: 14 \\
7: 34-15: 15 \\
7: 56-15: 15\end{array}$ & $\begin{array}{l}4 \\
4 \\
4 \\
4 \\
4 \\
4\end{array}$ & $\begin{array}{r}13 \\
12 \\
11 \\
9 \\
12 \\
13\end{array}$ & $\begin{array}{l}9 \\
8 \\
8 \\
7 \\
8 \\
9\end{array}$ & $\begin{array}{l}\text { General Air } \\
0 . E . \star \star \star \\
0 . E . \\
0 . E \text {. } \\
0 . E \text {. } \\
\text { General Air }\end{array}$ \\
\hline
\end{tabular}

*Denotes micrograms per cubic meter of air sampled.

**Denotes less than 4 micrograms, limit of detection for each filter.

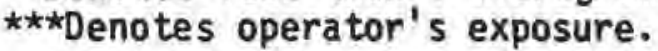

Criteria (micrograms per cubic meter)

Substance

Sulfur Dioxide
OSHA

13,000
NIOSH

1,300 
Page 13 - Boeing Verto1, HETA 82-272

TABLE II

Boeinq-Vertol Company

Philadelphia, Pennsylvania

Building 3-25

HETA 82-272

October 1982

Illumination measured at a $17^{\prime}$ detector to lamp distance

Area

Lamp Type

Il Tuminance

(1x)

Purchased parts stores

a) front storage racks (1 1amp)

HPSV

400

b) mid-point of 4 lamp cluster

HPSV

360

c) entrance of storage rack

(3 different locations)

d) Aisleway(s) of storage rack

HPSV

$10-170$

HPSV

$0-130$

(7 different locations)

e) open area-front of storage rack

HPSV

334

f) desk area directly under

Fluorescent

1900

lighting

q) $5^{\prime}$ from desk area not directly

Fluorescent

1700

under fluorescent lighting

\section{Packaging}

a) directly under HPSV lamps

(5 locations)

HPSV

$600-840$

b) desk areas under fluorescent lamps

Fluorescent

$1370-1410$

c) near desk areas

d) between rows of workers

(2 locations)

HPSV

$660-770$

HPSV

600-610

e) mid-point of 4 lamp cluster

HPSV

900

f) in lower light grid directly under HPSV

$350-360$

HPSV (1 amp spacing similar to purchased

parts storage - 2 locations)

From the IES (Illumination Engineering Society) Lighting Handbook, an exposure guideline for illuminance is 500 lux. 
Page 14 - Boeing Verto1, HETA 82-272

\author{
TABLE III \\ Demographic Data \\ Boeing-Vertol Company \\ Philadelphia, Pennsylvania \\ HETA $82-272$ \\ October 1982
}

\begin{tabular}{lccccccc} 
Area & Building & $\begin{array}{c}\text { HPSV } \\
\text { lamps }\end{array}$ & $\begin{array}{l}\text { Sulfur } \\
\text { boxes }\end{array}$ & $\begin{array}{c}\text { Number } \\
\text { seen }\end{array}$ & $\begin{array}{c}\text { Male/ } \\
\text { Female }\end{array}$ & $\begin{array}{c}\text { Age } \\
\text { Ave. Range }\end{array}$ \\
\hline $\begin{array}{l}\text { Packaging } \\
\begin{array}{l}\text { Purchase } \\
\text { Parts Store }\end{array}\end{array}$ & $3-25$ & + & - & 37 & $21 / 16$ & 38.2 & $24-60$ \\
& $3-25$ & + & + & 26 & $22 / 4$ & 41.8 & $23-60$
\end{tabular}

\title{
Pattern
}

Shop

$$
3-56
$$

$-$

19

$18 / 1$

$44.1 \quad 32-62$

$+=$ present

- = absent 
Page 15 - Boeing Vertol, HETA 82-272

TABLE IV

Boeing-Vertol Company

Philadelphia, Pennsylvania

HETA $82-272$

October 1982

Prevalence of reported symptoms

(Packaging vs Purchase Parts Stores)

Symptom

Packaging(37)

Purchase Parts

Stores(26)

t)

(\%)

(\%)

\begin{tabular}{|c|c|c|c|c|c|}
\hline $\begin{array}{l}\text { Eye blurring } \\
\text { Eye irritation } \\
\text { Eyes hot } \\
\text { Colors not correct } \\
\text { General eye fatigue, } \\
\text { strain }\end{array}$ & $\begin{array}{r}11 \\
16 \\
11 \\
2 \\
11\end{array}$ & $\begin{array}{l}(30) \\
(43) \\
(30) \\
(5) \\
(30)\end{array}$ & $\begin{array}{r}11 \\
18 \\
16 \\
5 \\
16\end{array}$ & $\begin{array}{l}(42) \\
(69) \\
(62) \\
(19) \\
(62)\end{array}$ & $\begin{array}{l}\text { N.S * } \\
0.05<p<0.1 * \\
0.01<p<0.02 \text { * } \\
\text { N.S. ** } \\
0.01<p<0.02 \text { * }\end{array}$ \\
\hline $\begin{array}{l}\text { Headache } \\
\text { Nausea } \\
\text { Difficulty maintaining } \\
\text { attention }\end{array}$ & $\begin{array}{l}6 \\
3 \\
3\end{array}$ & $\begin{array}{l}(17) \star * \star * \\
(8) \\
(8)\end{array}$ & $\begin{array}{l}6 \\
1 \\
1\end{array}$ & $\begin{array}{l}(23) \\
(4) \\
(4)\end{array}$ & $\begin{array}{l}\text { N.S. ** } \\
\text { N.S. ** } \\
\text { N.S. ** }\end{array}$ \\
\hline $\begin{array}{l}\text { Depression, anxiety } \\
\text { Crying episodes } \\
\text { Noticed loss of taste } \\
\text { Noticed loss of smell } \\
\text { Tightness in chest }\end{array}$ & $\begin{array}{l}2 \\
1 \\
0 \\
0 \\
1\end{array}$ & $\begin{array}{l}(5) \\
(3) \\
(0) \\
(0) \\
(3)\end{array}$ & $\begin{array}{l}4 \\
3 \\
3 \\
7 \\
3\end{array}$ & $\begin{array}{l}(15) \\
(12) \\
(12) \\
(30) \\
(12)\end{array}$ & $\begin{array}{l}\text { N.S. } \star \star \\
\text { N.S. } \star \star \\
0.0656 \star \star \\
0.0012 \star \star \\
\text { N.S. ** }\end{array}$ \\
\hline
\end{tabular}


Page 16 - Boeing Verto1, HETA 82-272

$$
\begin{gathered}
\text { Table V } \\
\text { Boeing-Vertol Company } \\
\text { Philadelphia, Pennsylvania } \\
\text { HETA 82-272 } \\
\text { October } 1982 \\
\text { Prevalence of reported symptoms } \\
\text { (Packaging vs Pattern Makers) }
\end{gathered}
$$

\begin{tabular}{llllll} 
Symptom & \multicolumn{2}{l}{ Packaging(37) } & \multicolumn{2}{l}{ Pattern-Makers(19) } & $\begin{array}{l}\text { Test of } \\
\text { Significance. }\end{array}$ \\
\hline Eye blurring & $\#$ & $(\%)$ & $\#$ & $(\%)$ & \\
Eye irritation & 11 & $(30)$ & 1 & $(5)$ & 0.0337 \\
Hot eyes & 16 & $(43)$ & 0 & $(0)$ & $0.01<p<0.001$ \\
Colors not correct & 11 & $(30)$ & 2 & $(11)$ & N.S. \\
Heacache & 2 & $(8)$ & 0 & $(0)$ & N.S. \\
Nausea & 6 & $(17) \star \star$ & 1 & $(5)$ & N.S. \\
Difficulty Maintaining & 3 & $(8)$ & 1 & $(5)$ & N.S. \\
attention & 3 & $(8)$ & 0 & $(0)$ & N.S. \\
Depression, anxiety & 2 & $(5)$ & 1 & $(5)$ & N.S. \\
Crying episodes & 1 & $(3)$ & 0 & $(0)$ &
\end{tabular}

\footnotetext{
N.S. =Not significant

* =Fisher's exact test, 1 tail

** =only 36 respondents-left blank by 1 respondent
} 
Page 17 - Boeing Vertol, HETA 82-272

$$
\begin{gathered}
\text { TABLE VI } \\
\text { Boeing-Vertol Company } \\
\text { Philadelphia, Pennsylvania } \\
\text { HETA } 82-272 \\
\text { October } 1982 \\
\text { Prevalance of reported eye symptoms } \\
\text { Packers } \\
\text { Pattern Makers }
\end{gathered}
$$

Reporting 2 or

more eye symptoms

Reporting less than

2 eye symptoms

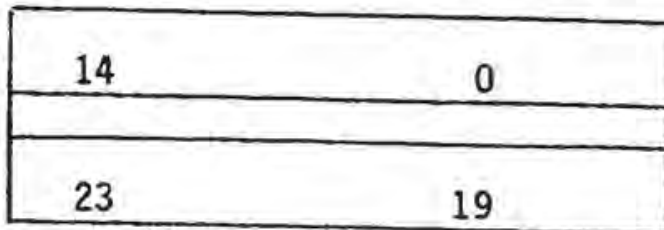

14

42

37

19

56

$X^{2}(C$ hi square $)=7.67$ (Yates correction)

$P<0.01$ 
Page 18 - Boeing Verto1, HETA 82-272

TABLE VII

Farnsworth-Munse11 100-Hue test scores
(Square root transformed)

Boeing-Vertol Company

Philadelphia, Pennsylvania

HETA $82-272$

A. Test performed first under standard light source $(n=4)$

\begin{tabular}{llcrr} 
\# & HPSV Score & & Std Light Source & Diff \\
\cline { 2 - 3 } 1 & 10.0 & 6.6 & 3.4 \\
2 & 11.3 & 14.0 & -2.7 \\
3 & 8.7 & 6.0 & 2.7 \\
4 & 14.1 & 10.6 & $\underline{3.5}$ \\
\hline
\end{tabular}

mean $+S . D=1.73+2.97$

$t=1.16, p>0.05, d \bar{f}=3$

B. Test performed first under HPSV lamps first $(n=6)$

\begin{tabular}{llcll}
$\#$ & HPSV Score & & Std light source & Diff \\
\cline { 4 - 5 } 1 & 10.4 & 10.0 & 0.4 \\
2 & 11.8 & 6.3 & 5.5 \\
3 & 10.0 & 8.0 & 2.0 \\
4 & 8.7 & 6.0 & 2.7 \\
5 & 12.2 & 12.2 & 0.0 \\
6 & 13.3 & 9.2 & 4.1
\end{tabular}

Overall; mean + S.D. $=2.16+2.36$

Mean + S.D. $=2.45+2.12$

$t=2.8 \overline{3}, p<0.05, d f=\overline{5}$ $t=2.8 \overline{9}, 0.01<p<0.02, d f=9$

* for those with no evidence of defective color vision only 
Page 19 - Boeing Vertol, HETA 82-272

\section{Appendix I}

Text of four eye-related statements on self-administered questionnaire requiring Yes or No answer *

1. Une or more of the following: blurred vision, double images, hard to focus

2. One or more of the following eye irritation problems: "eyes are painful, itchy, drying, gritty, watery or burning"

3. One or more of the following eye fatigue problems: "eyes are tired, hot, heavy, achy or strained"

4. One or more of the following: changes in your ability to see colors, colored fringes around objects, colors do not look quite correct

* These statements are part of a questionnaire developed by NIOSH's Division of Biomedical and Behavioral Science (DBBS) for use in evaluating visual symptoms in visual display operators. 


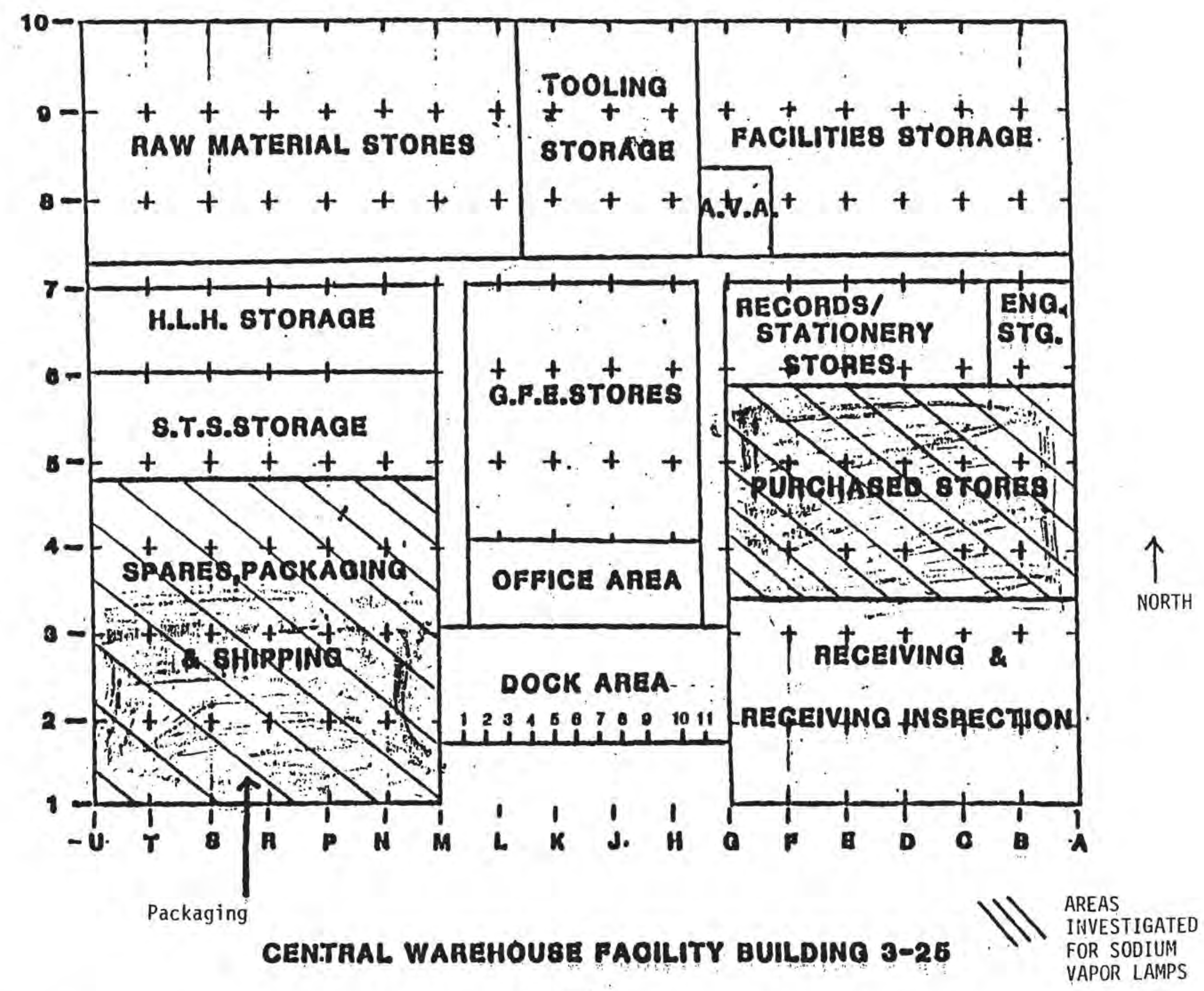

Figure 1 


\section{FIGURE 3}

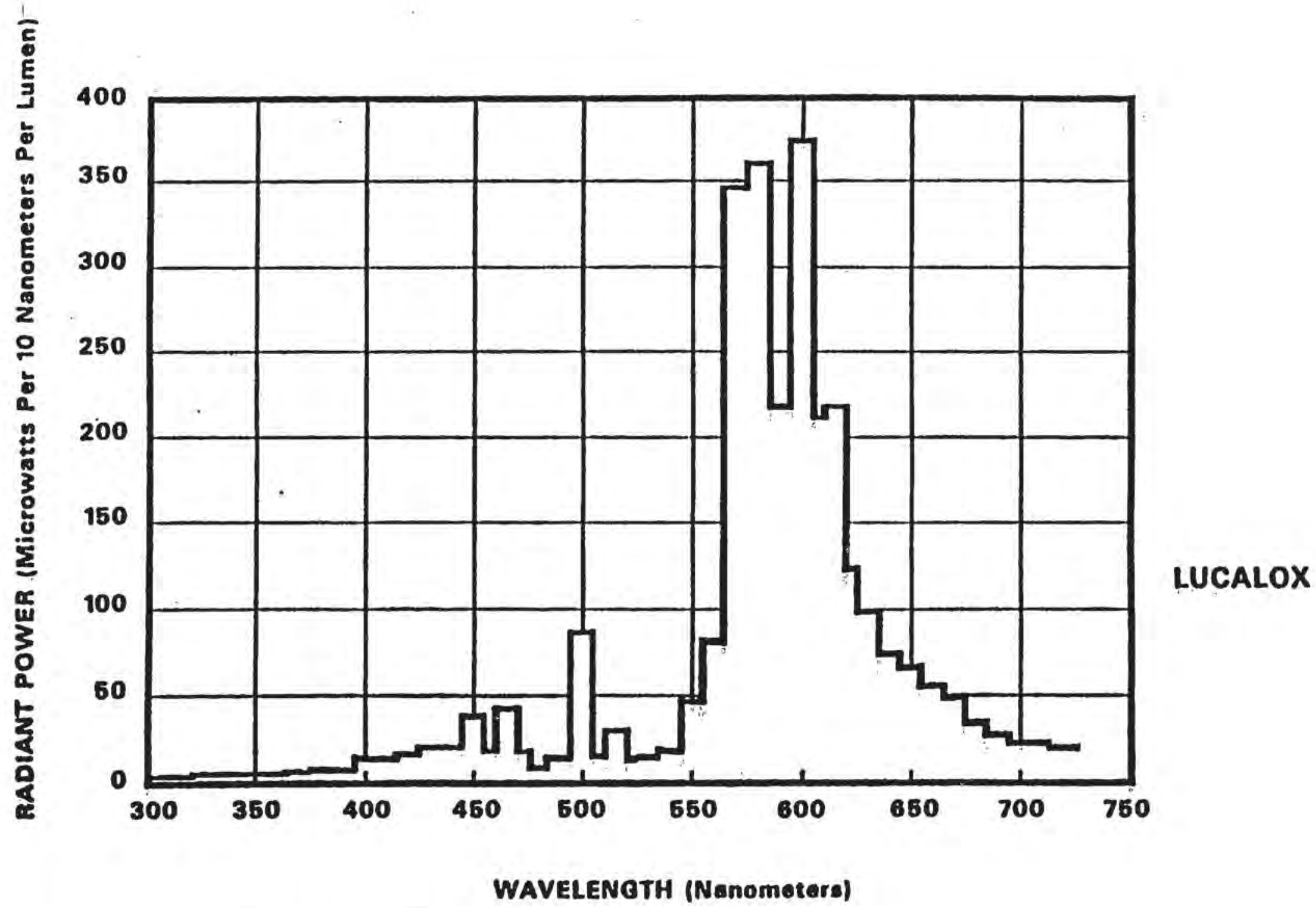

Figure 3. TYPICAL SPECTRAL EMISSION OF $400 \mathrm{H}$ HIGH PRESSURE SODIUM VAPOR LAMP 